\title{
THE EMPLOYEE STIMULUS AND RELATIONSHIP EFFICIENCY
}

\author{
Dr.C K GOMATHY . Ms.B.VARSHA , Ms.B.VARSHINI , Ms.N.BHAVYA KEERTHI
}

Sri Chandrasekharendra Saraswathi Viswa Mahavidyalaya , Kanchipuram

\begin{abstract}
:
The study investigates that the Impact of the Employee Motivation on Organization Productivity of some selected handloom firms in State of Kerala. The majority of the organizations are competing to survive in this volatile and fierce market environment. The Motivation and the performance of employees are essential tools for the success of an any organization in the long run. On the hand, measuring performance is critical to organization's management, as it highlights the evolution and achievement of the organization. On the other hand, having a positive relationship between employee motivation and the organizational effectiveness, reflected in numerous studies. The literature shows that the factors such as empowerment and the recognition will increase the employee motivation. If empowerment and the recognition of employees is increased, their motivation to work will also improve, as well as their accomplishments and the organizational perform.
\end{abstract}

Keywords: Employee Motivation, Organizational performance, Empowerment, Market Environment.

\section{INTRODUCTION}

Employee provocation is the position of energy, commitment, and creativity that a company's workers bring to their jobs. Whether the frugality is growing or shrinking, chancing ways to motivate employees is always an operation concern. Contending propositions stress either impulses or hand involvement (commission). Employee provocation can occasionally be particularly problematic for small businesses. The proprietor has frequently spent times erecting a company hands-on and thus finds it delicate to delegate meaningful liabilities to others. All associations want to be successful, indeed in current terrain which is largely competitive. Thus, companies irrespective of size and request strive to retain the stylish employees, admitting their important part and influence on organizational effectiveness. In order to overcome these challenges, companies should produce a strong and positive relationship with its workers and direct them towards task fulfilment. In order to achieve their pretensions and objects, associations develop strategies to contend in largely competitive requests and to increase their performance. Nonetheless, just a many associations consider the mortal capital as being their main asset, able of leading them to success or if not managed duly, to decline. However, the association cannot attain success Kerala has a longstanding tradition of weaving and handloom product, dating back to hundreds of times, If the employees aren't satisfied with their jobs and not motivated to fulfill their tasks and achieve their pretensions. Over the times the assiduity has lowered; low stipend and query in the employment pattern has left needlewomen in a state of total despair. Thousands of looms taradiddle idle and the future of this age-old tradition looks bleak. 


\section{LITERATURE REVIEW}

Bartol and Martin (1998) recall motivation a effective device that boosts behavior and triggers the tendency to continue. In different words, motivation is an inner power to fulfill an unhappy want and to acquire a sure intention. It is likewise a technique that starts offevolved thru a physiological or mental want that stimulates a overall performance set through an objective. As as compared to monetary sources, human sources have the functionality to create competitive gain for his or her corporations.

As Kalimullah (2010) advised, a stimulated worker has his/her dreams aligned with the ones of the agency and directs his/her efforts in that course. In addition, these corporations are greater successful, as their personnel constantly search for approaches to improve their paintings. Getting the personnel to attain their complete capacity at paintings beneathneath stressful situations is a difficult challenge, however this will be accomplished through motivating them.

Mary (1996) explains organizational effectiveness because the volume to which an agency fulfills its objectives, through the use of sure sources and without putting pressure on its members. The intention version defines organizational effectiveness relating to the volume to which an agency attains its objectives (Zammuto, 1982), at the same time as the machine aid version defines it in phrases of the bargaining electricity of the agency and its cappotential to make the most the surroundings whilst obtaining precious sources (Yuchtman, 1987).

Jennifer and George (2006) described motivation as a intellectual pressure that governs the course of an individual's behaviour in an agency, an individual's stage of effort, and an individual's stage of willpower whilst confronted with obstacles. In addition she said that even with suitable techniques and administrative systems in place, an agency can simplest be effective if its personnel are sufficiently stimulated to carry out at better levels.

Hellriegel (1996) considered motivation as any effect that brings out, guides, or sustains a person`s intention-directed behaviours. Ivancevich (1994) Suggested that motivation refers to the ones set of forces that triggers sure behaviours and regulates its form, course, depth and duration. Obikeze (2005) considered motivation because the system of guiding an worker`s actions closer to a specific stop through the manipulation of rewards.

Kreitner (1995) defined motivation because the intellectual system giving behaviours the willelectricity,power, and tendency to behave in a sure manner on the way to reap sure unhappy needs. Young (2000) additionally advised that motivation might be described when it comes to forces inside personnel that justifies the levels, directions, and backbone as regards efforts they dissipate in the workplace

\section{RESEARCH OBJECTIVES}

i.Determine the impact of worker wellbeing on the extent of effectiveness of the workers.

ii.Determine the impact of worker dating with managers on the extent of performance of the workers.

iii.To decide the elements that boom motivation of personnel in an organisation

iv. Examine the impact of education and profession improvement on the extent of performance of Employee in handloom industry. 
v.To look at the connection among worker motivation and organizational overall performance or company growth.

\section{IV.RESEARCH METHODOLOGY}

This paper is ready upon secondary records. The records required is accumulated from the posted and unpublished data and from the net reassets anywhere necessary. Datas additionally accumulated from the direct interplay of the personnel from the handloom enterprise.

\section{Handloom enterprise.}

Kerala handloom enterprise contains a important position in states economic system in addition to withinside the discipline of employment. A very massive quantity of looms are positioned in rural areas. The rhythm of handloom may be heard in nearly each village in Kerala. There are women and men weavers for whom weaving is a manner of life. In early days majority of handloom weavers observed the hereditary line. The fundamental groups engaged in weaving are saliyas and devangas. With the to be had data it's far clean that the saliyas and devangas migrated from the nearby

princely states. During the sunrise of twentieth century, the Sree Narayana motion influenced Kerala society via way of means of and massive prompting the caste primarily based totally way of life to alternate closer to secular and present day industrious way of life in order that many human beings from conventional Thiyya/Ezhava community had taken up their employment in Handloom Industry to take away the toddy tapping to reply with the recommendation of Sree Narayana Guru. These adjustments additionally have its very own mark in making the existing form of Kerala Handloom Industry.
Balaramapuram, being best-recognised locations in Kerala for handloom, possibly holds the monopoly over the conventional kasavu mundu (white cotton dhotis) and settu mundu (or mundum neriyathum). The subculture of weaving in Balaramapuram owes its patronage to the royal own circle of relatives of Travancore, which dates lower back to the cease of the 18th century while Maharaja Balarama Varma added weavers from what's now Valiyur in Tamil Nadu to weave garb for the royal own circle of relatives. Traditional Balaramapuram textiles have a gold zari border and normally a easy zari stripe on the cease, and are generally woven from herbal cotton yarn.Recently, experiments were performed with the patterns, along with weaving the equal designs the use of colored yarn for the weft, and the an increasing number of famous mural portray sarees - where cloth paints are used to recreate conventional Kerala temple artwork at the pallu of the saree. Given the mild weight and coarse texture of the cotton cloth, those textiles are best for the warm and humid weather in Kerala.

Chendamangalam Handloom The array of handloom fabric woven in Chendamangalam is tons similar to what one unearths in Balaramapuram, however with less emphasis on kasavu patterns. Instead, the standard Chendamangalam mundu or settu mundu has colored borders with an identical shade stripe, with most effective small quantities of kasavu for ornamentation. Like in different elements of Kerala, weavers in Chendamangalam had been under professional patronage of the feudal own circle of relatives of Paliam, who served because the leader ministers for the Rajas of Cochin. In phrases of the real process, Chendamangalam textiles are woven on body looms, and their texture is barely heavier than what 
one might locate withinside the equal types of fabric from Balaramapuram.

Kuthampully sarees are the maximum seen fashion outdoor the state. These sarees are quite famous in Kerala as well, given the style of jacquard designs that they may be generally Ornamented with - placing them aside from sarees woven someplace else withinside the state. Since Kuthampully sarees are normally woven the use of half-high-quality zari, this continues down at the fee of the very last product and provides to its popularity. Another distinctiveness of this layout is that the kasavu border does now no longer increase all the manner to the border, and this hole is white. Like maximum different locations in Kerala, the sarees woven right here are normally off-white in color,attributable to using undyed cotton yarn. Kuthampully weavers have their roots withinside the Devanga Chettiar network from Mysore. They got here below the patronage of the Kochi royal family, and firstly had woven fabric completely for the individuals of the palace -just like the weavers from Balaramapuram.

Kasargod and people woven in Mangalore technically it's the equal layout for the maximum part, that's woven all of the manner from Kannur to Mangalore. Kasaragod's weavers are firstly from the Padmashaliya network, who have been firstly from Mysore.Surprisingly, there appears to be tons extra hobby withinside the Kasargod saree than its counterpart in Mangalore. Kasargod sarees have were given a GI tag whilst Mangalore sarees do now no longer despite Karnataka having extra GI merchandise than another state. Kasargod sarees are the notable exception to the famous photograph of the Kerala saree being herbal cotton and embellished with kasavu - instead, a number of colorations are famous and there's a loss of any zari ornamentation. Having stated that, the layout aesthetic stays quite simple, tons in line with what one might assume of the quite sober alternatives in Kerala. Vat dyes are normally used for Kasaragod sarees, attributable to the color fastness compared to maximum different commercially to be had dyes.

\section{Concept of motivation.}

Motivation is mental forces that decide the path of someone's behaviour in an organization, someone's degree of attempt and someone`s degree of persistence (Jones \& George 2008). The idea of motivation may be broad; however, in step with Jones \& George (2008), there are 3 fundamental additives of motivation which might be path, depth, and persistency. Direction is a intention that forces an character to carry out an act to gain it. A intention is selected consciously or unconsciously through an character. There are elements that affect someone in deciding on the intention, together with each inner and outside elements, and the very last intention is the excellent one selected amongst cappotential alternatives. The depth is the extent of determination or attempt placed through an character withinside the technique of accomplishing the intention; how difficult an character has tried, and what sort of energy, time, money, or another intellectual or bodily matters have been used in the course of the technique to gain the intention. Persistence is the capacity of an character to keep the incentive thru instances despite the fact that limitations may also exist (Robbins and Judge 2013). It isn't an exaggeration to mention motivation is the center to being successful. A motivated character is possibly to willingly placed extra attempt into doing a challenge and an awesome end result is within expectations. When dreams are achieved, it drives a sense of being glad 
and enjoyment for the personnel and creates a nice operating attitude withinside the workplace.

\section{V.MOTIVATION METHODS}

There are many approaches to inspire personnel in nowadays`s running environment. Companies globally had been the use of distinctive techniques and technique which will enhance personnel motivation. However, it appears that evidently the exceptional motivator for personnel is some thing that is certainly essential of their lives. Furthermore, distinctive People may have distinctive values and tactics and, consequently, being capable of recognize personnel wishes and the use appropriate motivating strategies can assist boom the extent of motivation (Gleeson 2016).

According to Jan Ketil Arnulf"s article "Money as a Motivator" on Fudan University School of Management (2014), cash is deemed to be the exceptional motivator to any individual.Looking returned to the ancient time, it's miles cash that prompted large variations between personnel running in inhuman situations withinside the early business revolution and the ones running in slavesituations withinside the countryside. For individuals who participate withinside the "paid employee" system, the cash manner greater than simply itself; it additionally manner freedom and prosperity. That is why many human beings looking to circulate to business areas with the desire to enhancing their lives and running situations. With that prospect of revenue, nowadays many younger human beings are nevertheless striving from poorer to higher residing situations, from low to high schooling considering they assume it's miles the most effective manner to make certain a rich future (Arnulf 2014).
But is cash the exceptional and most effective motivator? Or are there any of motivators which have handed the cash motivator? Considering from any other perspective, we, as human beings, paintings for cash, however additionally for plenty different matters too, along with fulfillment, recognition, development,increase, duty, and the paintings itself (Herzberg 1987) .

Employee empowerment has been promoted as a manner to boom motivation (Kaplan \&Norton 1992, 1996). Empowerment offers personnel a sense of control, performance and effect. It creates a experience of freedom in making picks and the approaches the way to paintings, and paintings involvement; the sensation of duty and the cappotential to perform paintings in a satisfactory manner; and the sensation of fulfillment while the project is performed inside expectations and with preferred outcomes. Many research have proven that personnel with high empowerment motivation have better degree of labor motivation, which correspondingly effects in higher organizational productiveness and performance (Thomas \& Velthouse 1999; Koberg, Boss, Senjem \& Goodman 1999)

Achievement motivation is known as the want for fulfillment (Elliot \& McGregor 1999). It is the want for fulfillment and shows the wish of reaching excellence. Achievement may also range relying on distinctive human beings. For example,

it's miles the want for amusement and success to have a paintings-lifestyles balance, to sense engaged and glad with the paintings however nevertheless capable of revel in significant lifestyles to the fullest. Or it's miles simply approximately the effect their paintings has had on e.g. society and, environment. 
Feeling which you are creating a difference, converting the arena in a advantageous manner, and making it a higher area to stay is sincerely a effective motivator (Jex \& Britt 2008) Advancement as a motivator shows the possibilities of being promoted to better position, having better revenue and greater blessings withinside the company. Not all personnel proportion the equal development motivation, consequently know-how every employee's wishes and supporting them to attain the glad drivers is likewise a manner to motivating personnel.

Growth motivation is pretty just like development motivation considering it's miles one in all the motivators that enables hold the personnel. However, the definition is broader and it's miles notmost effective pretty much profession merchandising or higher revenue and blessings. Good personnel are enthusiastic, eager, determined, and above all, ambitious. They are continually searching out higher possibilities to grow, to accumulate greater knowledge, to examine new skills, to widen their network, and to undertaking themselves with distinctive positions. Providing and stimulating personnel increase motivation is critical approach of growing the extent of motivation (Lipman 2014)

The work itself is likewise a contributor to worker motivation. There is a reality that an worker may sincerely love his or her task, is happy with the pay, and has good relationships with his/her colleagues, however nevertheless unearths the paintings itself absolutely uninteresting and uninspiring. A satisfied worker may also stay, however in case you actually need to inspire the personnel,

create exciting paintings and allow them to have interaction with it. This way forming robust paintings cultures,encouraging innovative questioning and innovation, and especially, heading off unhealthy, unequal and impotent running environments (Landrum 2015)

Finally, regardless of the task is and regardless of what your role is, it's miles very critical to an worker that his/her efforts are identified. If an worker has been spending a variety of time running on a task, or is even simply inclined to assist out the alternative co-people, provide them applause and display them your gratitude. It may be understood that it isn't simply approximately giving praise.If the efforts of an worker are identified, he/she can be able to sense fulfillment and fulfilment and retain to excel withinside the paintings. However, it's miles important to keep in mind that the popularity as a motivator may also range amongst personnel as one may growth the paintings productiveness after being identified at the same time as one is the opposite.

By running intently with personnel, you may also realize how they react to recognition, hence being capable of off a becoming manner of appreciation (Health area 2017).

\section{FINDINGS AND RECOMMENDATIONS}

The have a look at consequences display that during general, the respondents are stimulated of their paintings.

Money, private growth, and a paintings-lifestyles stability are what inspire them the most. They revel in the ability of paintings, the hard and exciting developments it brings, and a good courting with their supervisors and colleagues.

They have clean dreams, priorities, and targets at paintings plus enough running facilities. They are stimulated to provide the great attempt and meet the set dreams each day. Above all, they may be satisfied with what they may be presently doing and 
satisfied to advocate their enterprise as a great location to paintings to others.

However, there nevertheless exist a few elements that want to be advanced as a way to growth personnel motivation. For examples, in step with the consequences, the respondents skilled a low charge for empowerment. It is probably the effect of poor paintings involvement, low obligation level, or a loss of freedom in making alternatives and the manner to enforce tasks. Furthermore, the supply of promoting possibilities must be better and a clean, united, and a completely unique enterprise subculture wishes to be described and practices well.

In addition, offering task rotation, enhancing control style, and having powerful verbal exchange in the enterprise also are approaches to a better worker motivation level.

They must offer an ecosystem for the attainment of excessive productiveness, with a view to in flip provide personnel a sense of satisfaction.Employees must receive the possibility to make a contribution their thoughts to the affairs of the enterprise as this could increase their morale and therefore cause better productiveness.

Management must make wonderful attempt closer to enhancing and keeping powerful verbal exchange machine among the 3 stages of control (top, center and low) and subordinates, in order that people could be acquitted of what's anticipated of them through the control.

Management need to make efforts to enhance salaries, running conditions, process security, process dissatisfaction and negative supervision to positive trendy so one can make personnel experience happy approximately their process.
Management need to additionally attempt to make certain that each one personnel interact in schooling packages to collect new abilities and still have identical possibility to make use of their abilities and competencies.

Management need to ensure that profession improvement possibilities are clearly communicated to personnel. An set up profession route and an good enough improvement plan need to be installed region for personnel, improvement packages need to be connected to every personnel profession desires and not simply the organization's desires. Employees need to be decided on for backed schooling packages pretty and justly.

Organizations need to make certain that overall performance control offers good enough information approximately electricity and weaknesses of personnel in shape of comments from worker reviews Managers need to preserve out the promise of praise as soon as the goal is achieved, because behaviour, that is seemed to be rewarded, will have a tendency to be repeated.

\section{CONCLUSION}

Recognition and empowerment play an critical element in improving worker motivation toward organizational responsibilities. By appreciating the personnel for his or her paintings finished and giving them participation in choice making, internally satisfies them with their process, organization and organizational environment. Thus their enthusiasm and motivation toward accomplishment of responsibilities increases. Thus it's miles concluded that appreciation and reputation of personnel and personnel responsibilities fulfilment stimulates them toward running with more electricity and willpower to the organization. The encouraged personnel works pleasant in the 
hobby of the corporations which leads them toward growth, prosperity and productivity. Thus the worker motivation and organizational effectiveness are immediately related

\section{VIII.REFERENCE}

1.Dr.C K Gomathy, Article: A Study on the recent Advancements in Online Surveying, International Journal of Emerging technologies and Innovative Research ( JETIR ) Volume 5 | Issue 11 | ISSN : 2349-5162, P.No:327-331, Nov-2018

\section{Dr.C.K.Gomathy,C K Hemalatha, Article: A}

Study On Employee Safety And Health

Management International Research Journal Of

Engineering And Technology (Irjet)- Volume: 08 Issue: 04 | Apr 2021

3. Dr.C K Gomathy, Article: A Study on the Effect of Digital Literacy and information Management, IAETSD Journal For Advanced Research In Applied Sciences, Volume 7 Issue 3, P.No-51-57, ISSN NO: 2279-543X,Mar/2018

4. Dr.C K Gomathy, Article: An Effective Innovation Technology In Enhancing Teaching And Learning Of Knowledge Using Ict Methods, International Journal Of Contemporary Research In Computer Science And Technology (Ijcrcst) E-Issn: 2395-5325 Volume3, Issue 4,P.No-10-13, April '2017

5.Dr.C K Gomathy, Article: Supply chain-Impact of importance and Technology in Software Release
Management, International Journal of Scientific Research in Computer Science Engineering and Information Technology ( IJSRCSEIT ) Volume 3 | Issue 6 | ISSN : 2456-3307, P.No:1-4, July-2018

\section{Author's Profile:-}

1.Ms.B.Varsha(11189A027), Student, B.E.

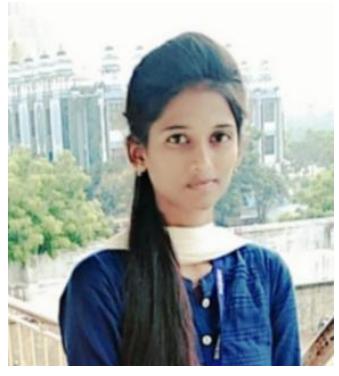
Computer Science and Engineering, Sri Chandrasekharendra SaraswathiViswa Mahavidyalaya deemed to be university, Enathur, Kanchipuram, India.

2. Ms.B.Varshini(11189A030) Student, B.E.

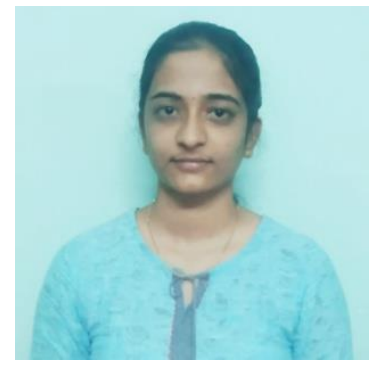
Computer Science and Engineering, Sri Chandrasekharendra SaraswathiViswa Mahavidyalaya deemed to be university, Enathur, Kanchipuram, India.

3.Ms.N.Bhavya Keerthi(11189A156) Student, B.E.

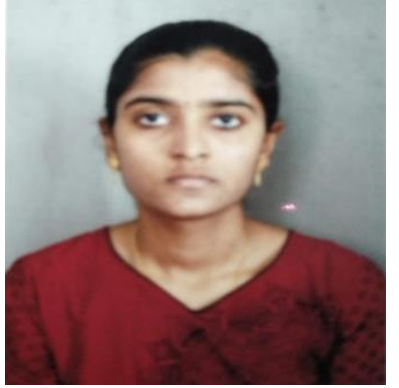
Computer Science and Engineering, Sri Chandrasekharendra SaraswathiViswa Mahavidyalaya deemed to be university, Enathur, Kanchipuram, India. 
4. Dr.C.K.Gomathy is Assistant Professor in

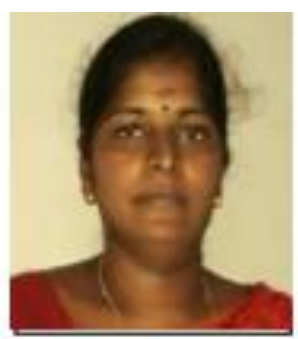

Computer Science and

Engineering at Sri

Chandrasekharendra

SaraswathiViswa

Mahavidyalaya deemed to be

university, Enathur,

Kanchipuram, India. Her area

of interest is Software Engineering, Web Services,

Knowledge Management and IOT. 